\title{
MECHANICAL BEHAVIOR ANALYSIS OF HOLLOW THRUST TAPERED ROLLER BEARING
}

\author{
T.Y Shang \\ SWPU \\ Student
}

\author{
Qi Qian \\ SWPU \\ Student
}

\author{
Y.P Long \\ SWPU \\ Student
}

\author{
Guojun Zhang \\ Beijing Locomotive \\ Depot, \\ Beijing Railway \\ Bureau
}

\begin{abstract}
The design of tapered roller hollow structure is very important to its mechanical properties. Reasonable hollow structure can effectively reduce the stress of tapered roller, improve its load-bearing capacity and prolong its service life. Unreasonable hollow structure may reduce its load-bearing capacity and lead to premature failure of thrust bearing, affecting the whole. Service life of screw drilling tools. In this paper, the different loads of tapered roller bearings with equal diameter are analyzed in order to obtain the instructive results.
\end{abstract}

Keywords- Mechanical Behavior, Hollow Thrust Tapered Roller Bearing

\section{INTRODUCTION}

The design of tapered roller hollow structure is very important to its mechanical properties. Reasonable hollow structure can effectively reduce the stress of tapered roller, improve its loadbearing capacity and prolong its service life. Unreasonable hollow structure may reduce its load-bearing capacity, and lead to premature failure of thrust bearings, affecting the service life of the whole screw drilling tool.

Many studies have found that hollow rollers have longer fatigue life than solid rollers. Even so, no reliable hollow roller body analysis model has been developed to study its fatigue life and determine the optimum percentage of hollow rollers under normal and tangential loads. In order to use fatigue life theory to determine the fatigue life of hollow rollers, stress and strain distribution should be studied and analyzed first. Different percentage of hollowness should be studied to determine the optimum percentage of hollowness for different loading conditions and materials.

\section{FINITE ELEMENT ANALYSIS OF 1 HOLLOW THRUST TAPERED ROLLER BEARING}

1. Based on the research needs, hollow tapered roller bearings are used in this study. The geometric size and material characteristics of hollow tapered roller bearings are analyzed by taking the shape size of NU317E solid tapered roller bearings as an example $^{[1]}$. Seven groups of models were established with hollowness of $40 \%, 45 \%, 50 \%, 55 \%, 60 \%, 65 \%$ and $70 \%$ respectively. Considering that the analysis of the whole bearing is complex and the calculation time is too long, in order to simplify the analysis, only $1 / 2$ bearing rollers, $1 / 4$ bearing outer rings and $1 / 16$ bearing inner rings are taken as finite element analysis models as shown in Figure 1. Bearing inner and outer rings and rolling elements are all made of Gr35 bearing steel with modulus of elasticity 210 $\mathrm{GPa}$ and Poisson's ratio 0.3. Material properties are created and sectional properties are allocated through the above parameters.

2. Create analysis step and field output, output stress, strain and contact. Then, the interaction property is created, and the contact between the surface and the surface is selected. The friction coefficient is set to 0.2 . The interaction surface is selected, with the outer surface of the inner ring and the inner surface of the outer ring as the main surface, and the conical rolling body as the contact pair from the inner surface.

3. The load and boundary conditions are created. Because the model is highly symmetrical, the symmetrical constraint boundary conditions are adopted to completely fix the bottom surface of the bearing outer ring, and the symmetrical constraints of $\mathrm{U} 1=\mathrm{UR} 2=\mathrm{UR} 3=0$ are applied to the inner ring cross section, the rolling body cross section and the outer ring cross section. In order to study the effect of hollowness on the mechanical properties of hollow tapered roller bearings under different working conditions, two kinds of loads were set up in this analysis, $24.3 \mathrm{KN}$ and $25 \mathrm{KN}$, which were converted into $25 \mathrm{MPa}$ and $50 \mathrm{MPa}$, and 4. The mesh size of bearing inner ring and bearing outer ring is 0.0015 . Finish the grid, as shown in Figure 2. 


\section{International Journal of Engineering Applied Sciences and Technology, 2019 \\ Vol. 4, Issue 3, ISSN No. 2455-2143, Pages 5-9 \\ Published Online July 2019 in IJEAST (http://www.ijeast.com)}

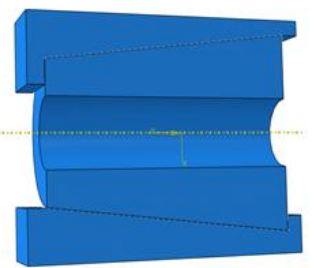

Figure.1

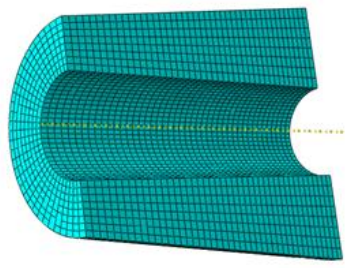

Figure.2
3D Model Finite element analysis model

III. MECHANICAL PROPERTIES ANALYSIS OF BEARINGS WITH DIFFERENT TYPES OF HOLLOW STRUCTURES

1. Different types of hollow structures

Fig. 3 is a sketch of the hollow structure of the tapered roller designed. Fig. 3 is a cylindrical hollow structure. The inner structure of the tapered roller is a cylinder. The structure is easy to process, but the wall thickness of the small end of the tapered roller is thinner than that of

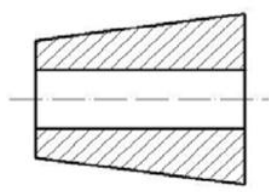

the large end.

Fig. 3 Circumferential Roller Profile

2. Finite Element Models of Different Hollow Structures

Because of the symmetry of the structure and load of tapered roller thrust bearing and the axisymmetric structure of single roller, the finite element model of the hollow tapered roller of this structure is established as shown in Fig. 4. The structure is based on the hollowness of the small end, the hollowness is $50 \%$, the lower end is the inner ring of the bearing, and the upper end is the outer ring of the bearing. According to the load-bearing conditions of thrust bearings, fixed constraints are imposed on the bottom of the inner ring, and all constraints are imposed on the inner cylinder of the inner ring and the outer cylinder of the outer ring of the bearing, except for the axial direction of the screw. A uniform load of $9 \mathrm{MPa}$ was applied on the upper surface of the bearing outer ring to simulate the working condition of $24.3 \mathrm{kN}$ axial load. Hexahedron element is used to mesh the model. Two contact pairs between the outer surface of tapered roller and the upper surface of bearing inner ring and the lower surface of bearing outer ring are established respectively, and the friction coefficient between them is set to be 0.2 . The material elastic modulus of each bearing component is $210 \mathrm{GPa}$, Poisson's ratio is 0.3 , and material density is $7800 \mathrm{~kg} / \mathrm{m} 3$.

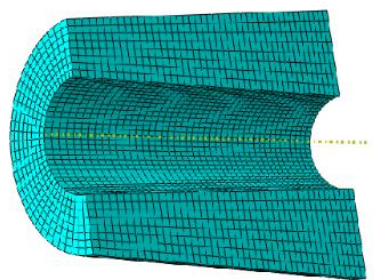

Figure 4 of Cylindrical Hollow Structure

3. Analysis of Mechanical Characteristics of Different Structures

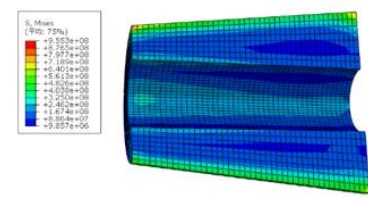

Fig. 5 Concentrated stress nephogram of tapered bearings with equal diameter

Fig. 5 shows the equivalent stress nephogram of bearing inner ring in thrust bearing. The distribution of equivalent stress in the inner ring of the bearing is the same. Along the radial direction of the inner ring, the equivalent stress increases gradually, but the large equivalent stress does not appear at the edge, but in the center.
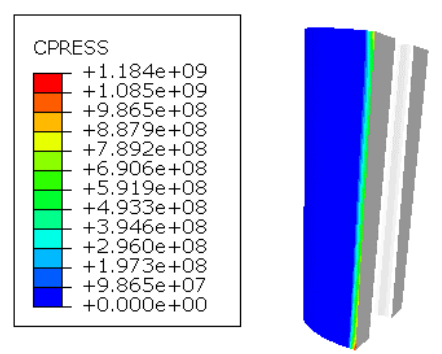

Figure 6 Contact stress nephogram of tapered roller

Figure 7 shows the contact stress nephogram of the hollow conical roller with equal diameter. It is obvious from the figure that the contact stress distribution of the conical roller is not uniform, especially at the small end of the roller, which aggravates the fatigue failure and wear of the small end, and makes the load-bearing of the whole roller uneven. Therefore, the hollow structure with equal wall thickness is formed. Reasonable . 


\section{International Journal of Engineering Applied Sciences and Technology, 2019 \\ Vol. 4, Issue 3, ISSN No. 2455-2143, Pages 5-9 \\ Published Online July 2019 in IJEAST (http://www.ijeast.com)}

\section{MECHANICAL PROPERTIES ANALYSIS OF BEARINGS WITH DIFFERENT HOLLOWNESS}

1. Equivalent Stress Analysis of Bearings with Different Hollowness

Equivalent stress is an important factor affecting the fatigue life of thrust bearings and evaluating the bearing capacity. Therefore, the equivalent stress is taken as an evaluation parameter of the influence of hollowness on bearing performance.

Figure 8 shows the equivalent stress nephograms of bearing rollers in thrust bearings with four different hollowness. The distribution of equivalent stress of bearing rollers in the first three structures is the same. Along the radial direction of the rollers, the equivalent stress gradually increases, but the large equivalent stress does not appear at the edge, but in the center. The equivalent stress of the roller in the fourth tapered roller bearing with equal wall thickness decreases gradually along the radial direction, and the maximum value appears near the end of the retaining wall.
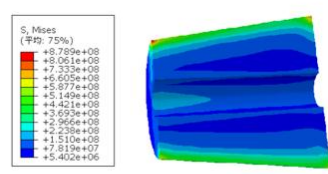

$k=30 \%$
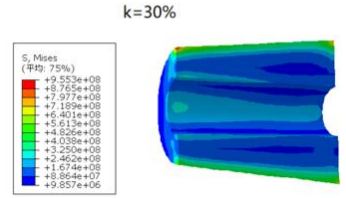

$k=50 \%$
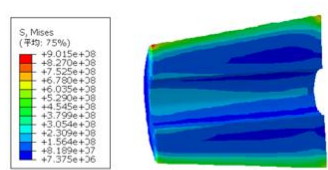

$k=40 \%$
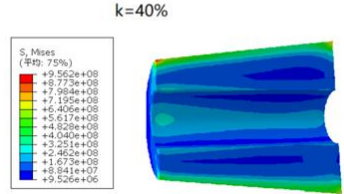

$k=60 \%$
Figure 8 Concentrated stress nephogram of bearings with different hollowness

Fig. 9 shows the equivalent stress distribution curves of tapered roller along the bus direction at different hollowness. From the graph, it can be seen that the stress distribution in the middle part of the tapered roller is more uniform, and the stress at both ends increases obviously, and the stress concentration occurs, that is, the "edge effect" exists. When the hollowness is less than $65 \%$, the equivalent stress of tapered rollers with different hollowness changes little; when the hollowness is greater than $65 \%$, the equivalent stress of rollers along the bus direction increases with the increase of the hollowness. When the hollowness of the roller is 0 , the equivalent stress at the large end of the cylindrical roller is larger than that at the small end. With the increase of the hollowness, the equivalent stress at the small end of the tapered roller is larger than that at the large end. And with the increase of hollowness, the stress distribution in the middle part of tapered roller becomes more uneven.

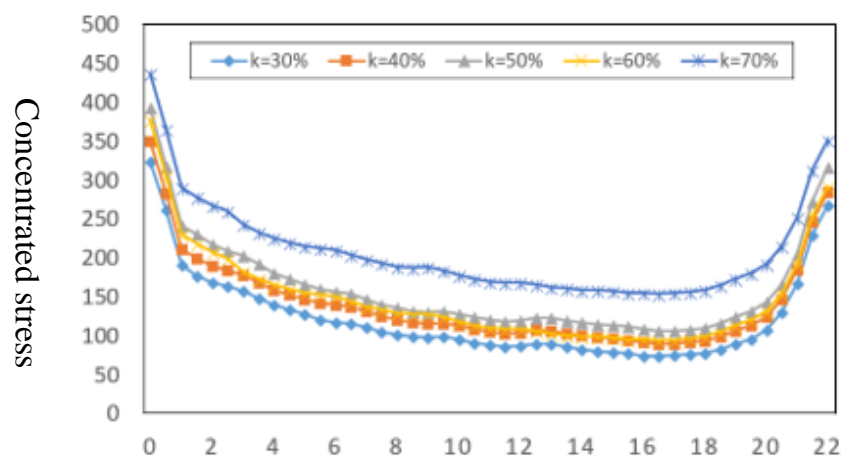

Bus Direction L/mm

Figure 9 Concentrated stress distribution of bearings with different hollowness

Fig. 10 shows the curves of the large equivalent stress of the inner ring, outer ring and hollow tapered roller varying with the hollowness. The large equivalent stress of bearing inner ring and outer ring decreases first and then increases with the increase of hollowness. When the hollowness is $60 \%$, it reaches a small value and is smaller than the large stress of solid roller. The large stress of hollow tapered roller is much larger than that of bearing inner and outer rings. When the hollowness is $65 \%$, the large equivalent stress of roller is small. When the hollowness is more than $70 \%$, the large stress of roller increases sharply. Therefore, the hollowness of tapered roller should not exceed $70 \%$.

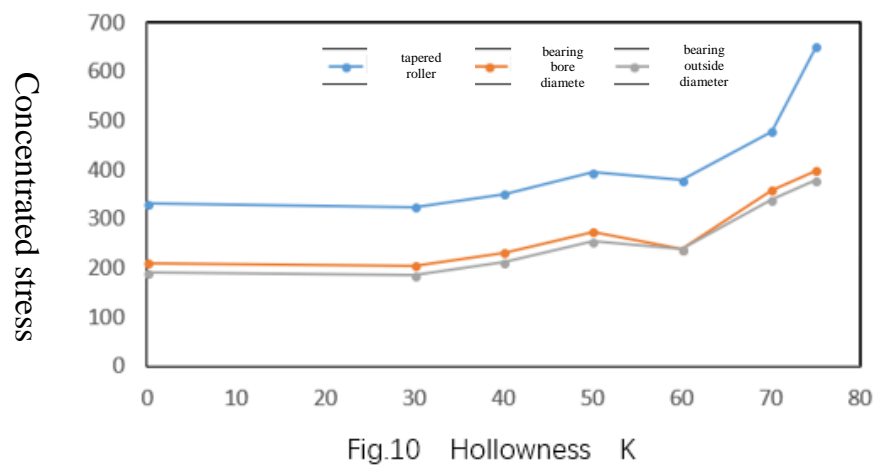

2. Contact Stress Analysis of Bearings with Different Hollowness

Fig. 11shows contact stress nephogram of tapered roller with hollowness of $30 \%, 40 \%, 50 \%$ and $60 \%$, respectively. It can be seen from the figure that with the increase of the hollowness, the stress of the inner wall of tapered roller increases gradually. When the hollowness is $50 \%$, the large contact stress of the roller appears on the inner wall. In 


\section{International Journal of Engineering Applied Sciences and Technology, 2019 \\ Vol. 4, Issue 3, ISSN No. 2455-2143, Pages 5-9 \\ Published Online July 2019 in IJEAST (http://www.ijeast.com)}

addition, the stress value of the small end is greater than that of the large end along the bus direction on the inner wall of the roller.

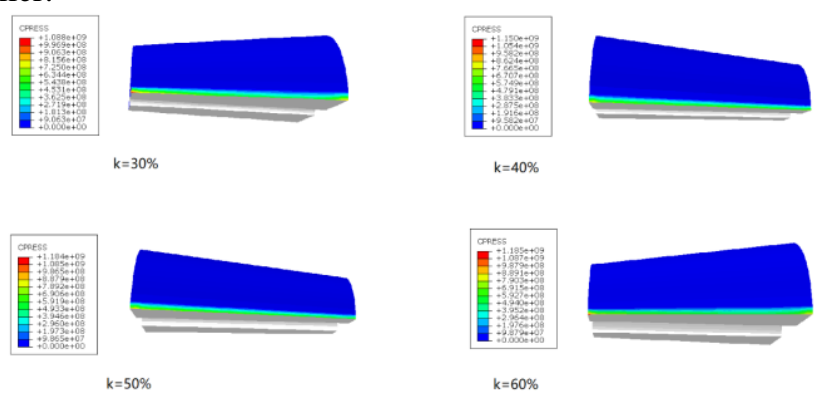

Fig. 11 Contact stress nephogram of bearings with different hollowness

Fig. 12 shows the contact stress distribution of tapered rollers with different hollowness. On the whole, the distribution of contact stress along the bus direction of tapered roller is different from that of equivalent stress. When the hollowness is less than $55 \%$, the contact stress at both ends of the roller still exists obvious stress concentration phenomenon, but with the increase of the hollowness, the large contact stress at both ends of the roller decreases gradually. With the increase of hollowness, the stress distribution in the middle part of the roller gradually becomes uneven, and the contact stress near the small end of the roller gradually increases, while the contact stress near the large end gradually decreases. When the hollowness is more than $65 \%$, the large contact stress of the roller appears near the small end of the roller, and the contact stress of both ends of the roller is still less than the middle part.

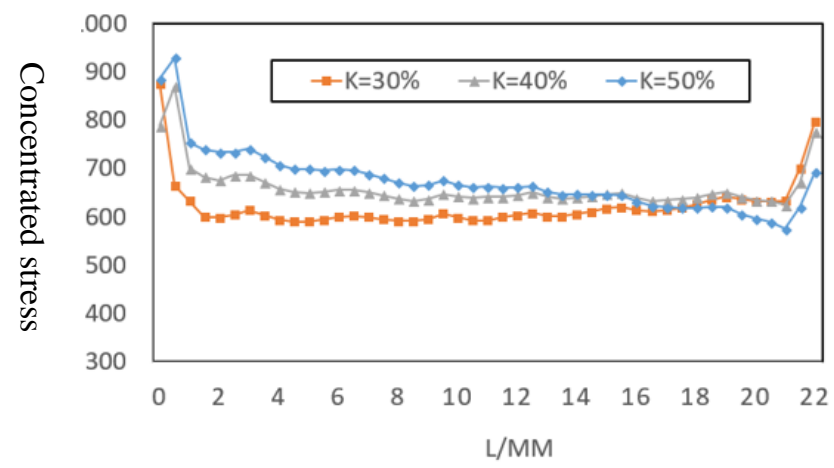

Fig. 12 Contact stress of rollers with different hollowness

\section{MECHANICAL PROPERTIES ANALYSIS OF BEARINGS UNDER DIFFERENT LOADS}

In this model, the dimension parameters of bearing are small end diameter D1 of $12.4 \mathrm{~mm}$, big end diameter D2 of $17.8 \mathrm{~mm}$ and axial length $\mathrm{L}$ of $22 \mathrm{~mm}$. Because the structure and load-bearing of thrust bearing and tapered roller are symmetrical, the $1 / 2$ model of a single roller is taken to calculate and establish. The contact model between roller and bearing upper and lower seat rings shows that the dimension parameters of bearing upper and lower seat rings are $25 \mathrm{~mm}$ in axial length and $6 \mathrm{~mm}$ in radial width. The number of rollers used in this paper is 18 . Therefore, the relationship between the radial load on the bearing and the surface pressure of the upper seat rings in this section is shown in Table 1.

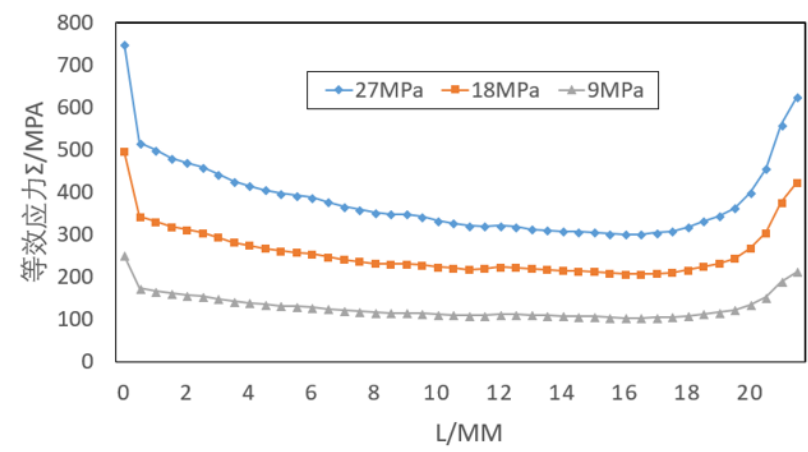

Fig. 14 Equivalent Force Distribution Diagram of Bearing under Different Pressure

\begin{tabular}{|l|l|l|l|}
\hline Radial load & $24.3 \mathrm{KN}$ & $48.6 \mathrm{KN}$ & $72.9 \mathrm{KN}$ \\
\hline Pressure & $9 \mathrm{MPa}$ & $18 \mathrm{MPa}$ & $27 \mathrm{MPa}$ \\
\hline
\end{tabular}

The distribution of load and equivalent stress is shown in Fig. 14. The equivalent stress at both ends of the hollow cylinder rolling body is the largest. The more the equivalent stress is in the middle, the smaller it will be and the more stable it will be. Under the pressure of $9 \mathrm{Mpa}$ to $28 \mathrm{MPa}$ on the upper ring, the variation range of the equivalent pressure of the bearing is almost the same.

\section{CONCLUSION}

In view of the problems existing in four-point thrust ball bearings, a tapered roller thrust bearing group for screw drilling tools is designed, and its feasibility is analyzed from the new trend of development of screw drilling tools and the characteristics of tapered roller thrust bearings. The calculation model of tapered roller thrust bearing is established in the finite element software, and the contact stress and equivalent stress are analyzed. It is found that there is a stress concentration phenomenon at both ends of tapered roller, namely "edge effect", while the stress distribution in the middle part of the roller is more uniform. Compared with the contact stress of the roller, the "edge effect" of the equivalent stress is more serious.

Acknowledgements

This work is supported by Luzhou Science and Technology Plan(2018-GTF-6) 


\section{International Journal of Engineering Applied Sciences and Technology, 2019 Vol. 4, Issue 3, ISSN No. 2455-2143, Pages 5-9 \\ Published Online July 2019 in IJEAST (http://www.ijeast.com)}

\section{REFERENCE}

[1] Zhang Jie, Liang Zheng, Han Chuanjun, et al. Design and contact analysis of deep hole hollow thrust tapered roller bearings [J]. Journal of Huazhong University of Science and Technology (Natural Science Edition), 2014 (6): 28-32.

[2] Yao Qishui. Theory and Application of Elastic Composite Cylindrical Roller Bearing Foundation Design [D]. Hunan University, 2016.

[3] Chapter Invention, Liu Sheming. Statistical analysis of screw drill tool failure [J]. Petroleum field machinery, 1998 (2): 31-34.

[4] Luo Jiwei, Zhang Junjie. Numerical solution of contact stress of tapered roller [J]. Bearing, 2004 (9): 1-3.

[5] Zhang Dezhen. Three-dimensional numerical simulation of elastic contact problems of tapered roller bearings [J]. Mechanical transmission, 2010, 34 (6): 23-25.

[6] Huang Longfa, Xu Zhenggong, Han Zhigang. Structural improvement design and finite element analysis of tapered roller thrust bearing [J]. Machinery, 2006, 33 (12): 58-61.

[7] Tonghua, Zhu Xiaohua, Shichangshuai. Working mechanics analysis and structural improvement of thrust bearings for screw drilling tools $[\mathrm{J}]$. Petroleum Machinery, 2010, 38 (4): 34-36.

[8] Zhou Jiqiang, Huang Zhiqiang, An Xianbin, et al. Failure analysis and improvement of bimetallic seal for bearing of high-speed cone bit [J]. Petroleum Mine Machinery, 2011, 40 (8): 50-53.

[9] Wei Yangang. A theoretical study on the load-bearing performance of a new type of rolling element bearing-deep hole hollow cylindrical roller bearing $[\mathrm{J}]$. Journal of Mechanical Engineering, 2005, 41 (2): 107-111.

[10] Miyuhong. Failure form of tapered roller bearings [J]. Bearings, 2006 (7): 37-39.

[11] Wu Feike. Contact stress analysis and crown design of tapered roller bearings [D]. Henan University of Science and Technology.

[12] Zhang Yongqi, Tan Qingchang, Zhang Qing. Roller contact stress analysis of tapered roller bearing of main reducer of automobile drive axle [J]. Bearing, 2008 (3): 1-4.

[13] Zhang Hongwei, Chen Jiaqing, Zhang Xiangdong. Numerical simulation of contact mechanics for hollow cylindrical roller bearings [J]. Bearings, 2011 (8): 1-6.

[14] Han Chuanjun, Zhang Jie, Liang Zheng. Design and analysis of thrust hollow tapered roller bearings for screw drilling tools $[\mathrm{J}]$. Journal of China University of Petroleum (Natural Science Edition), 2014, 38 (3): 123-128.

[15] Zhang Jie, Liang Zheng, Han Chuanjun, et al. Design and contact analysis of deep hole hollow thrust tapered roller bearings [J]. Journal of Huazhong University of Science and Technology (Natural Science Edition), 2014 (6): 28-32.

[16] Zhang Jie, Han Chuanjun, Yin Wenfeng. Bias loadbearing analysis of hollow cylindrical roller bearings based on ADINA [J]. CAD/CAM and manufacturing information, 2012 (Z1): 74-76. 